\title{
BILATERAL ACCESSORY RENAL ARTERIES
}

A. Vasanthi' ${ }^{1}$ K. P. S. Adinarayana ${ }^{2}$

\section{HOW TO CITE THIS ARTICLE:}

A. Vasanthi, K. P. S. Adinarayana. "Bilateral Accessory Renal Arteries". Journal of Evolution of Medical and Dental Sciences 2014; Vol. 3, Issue 06, February 10; Page: 1507-1511, DOI: 10.14260/jemds/2014/2016

ABSTRACT: Renal artery variations are more important for surgeons and clinicians. As these variations alter and influence the surgical procedures including intervention methods. These variations are associated with physiological and embryological changes which will alter the medical treatment. The present work is conducted in the department of anatomy, Andhra medical college, Visakhapatnam for 50 cadavers for a period of 3 years. In one case 3 additional renal arteries arising from abdominal aorta one on right, two on left side were found.

INTRODUCTION: The renal arteries usually arise from the abdominal aorta just below the origin of superior mesenteric artery, laterally or antero laterally (Williams). ${ }^{1,2}$ Renal artery variations are more frequently reported than other large vessels. Graves $(1956)^{3}$ described variations regarding renal arteries as an (a)accessory where arteries arise from abdominal aorta in addition to main renal arteries. (b) aberrant arising from sources other than abdominal aorta. Incidence of pre caval right renal arteries varies from $0.8 \%$ (Petit. P) ${ }^{4}$ to $5 \%$ Yeh et al. ${ }^{5}$ suggested that most of precaval right renal arteries were accessory lower polar arteries. In 2008 SHOJA.M.M et al. ${ }^{6}$ described prehilar pattern of renal artery. The embryological explanation of these variations has been presented and discussed by Keibel F \& Mall F7. Accessory renal arteries are found frequently on the left side. Their occurrence is as high as $30-35 \%$ of the cases. These arteries usually enter the upper or lower pole of the kidneys (Singh G, NGYK, Bay BH) ${ }^{8}$.

According to kadir et al. ${ }^{9}$ accessory renal arteries are of two types. The most common first type is where the accessory renal arteries enter into the renal hilum along with the main renal artery, the other type is where the accessory arteries enter directly into the capsule of polar regions. Ozkan et al. ${ }^{10}$ named second group of accessory renal arties as polar or aberrant arteries.

There are a few other renal vascular variations that must be differentiated from the accessory renal arteries (Netter FH, Shapter RK, Yonkman F F) ${ }^{11}$. Opinion of earlier authors differ in regard side of accessory renal arteries, some authors have reported a high frequency on the left side (Saldarriaga. B, Perez. AZ) ${ }^{12}$ while others (Nayak, Budhiraja) ${ }^{13,14}$ reported it to be more frequent on the right side. Lower polar arteries which typically pass in front of ureter are associated with a relatively higher incidence of hydronephrosis resulting from obstructions of ureter in uretro pelvic region (Anson.BJ) ${ }^{15}$.

The right renal artery that passes ventral to the inferior vena cava is important for pre surgical planning, because chances of injury especially during retroperitoneal approach are high when only the right gonadal vein is expected to lie in pre caval area. This anterior origin may also result in misidentification of vessels during laparoscopy, such as the inferior mesenteric, superior mesenteric or hepatic artery.

OBJECTIVES: Identification of anomalous vascular supply to the kidneys and their anatomical relationship to abdominal aorta and inferior vena cava and to represent their interpretation in surgical procedures. 
MATERIALS \& METHODS: During routine dissection conducted to undergraduate medical college students, Andhra Medical College, Visakhapatnam for a period of 3 years, were chosen for the present study (work) 50 cadavers were examined and in one cadaver accessory renal arteries, one on right side, two on left side identified.

CASE REPORT: An additional branch arising from abdominal aorta and reached the lower pole of right kidney. It is inferior accessory renal artery on right side. On left side a branch taking origin from abdominal aorta just above left renal artery and supplying the superior pole of the left kidney. It is superior accessory renal artery. Another branch arising from abdominal aorta 1 1/2 inch below the main left renal artery reaching the lower pole of the left kidney and it is called inferior accessory renal artery. In the present case we found 3 accessory renal arteries, the length of the main renal artery on right side $31 \mathrm{~mm}$, on left side $29 \mathrm{~mm}$. Single renal arteries was found in all other cases except this case.

\section{BILATERAL ACCESSORY RENAL ARTERIES}

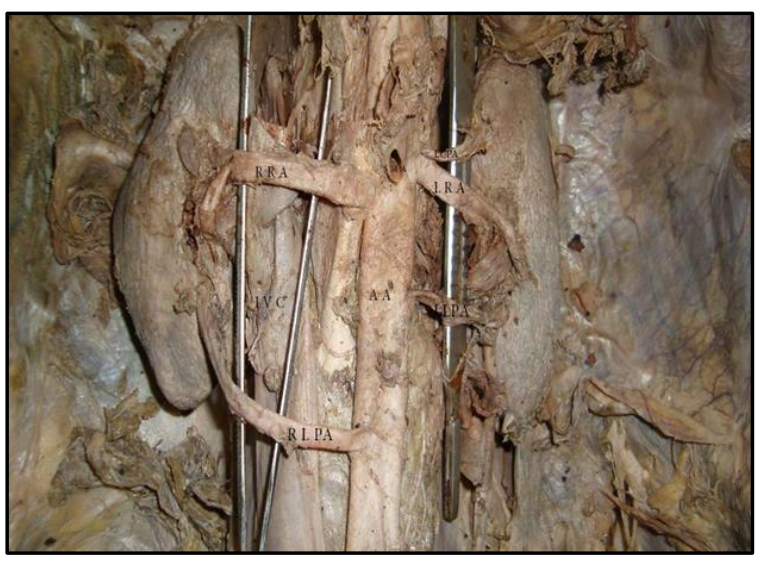

\section{ABBREVATIONS:}

1. RK- RIGHT KIDNEY

2. LK- LEFT KIDNEY

3. IVC- INFERIOR VENACAVA

4. AA- ABDOMINAL AORTA

5. SMA- SUPERIOR MESENTRIC ARTERY.

6. LRA- LEFT RENAL ARTERY

7. RRA- RIGHT RENAL ARTERY

8. RLPA- RIGHT LOWER POLAR(ACCESSORY) ARTERY

9. LUPA- LEFT UPPER POLAR (ACCESSORY) ARTERY

10. LLPA- LEFT LOWER POLAR (ACCESSORY) ARTERY

DISCUSSION: Variations of renal arteries are not uncommon. Abnormalities of renal arteries were studied by Dhar. P and Lal. $\mathrm{k}^{16}$. They found the mean length of the main renal artery was $31.05+/-12$ and $25.0+/-9.5 \mathrm{~mm}$ on the right and the left side respectively. Multiple (accessory) renal arteries were observed in $20 \%$ of the specimen with unilateral anomaly (15\%) being more commonly encountered than bilateral anomaly $5 \%$. The mean length of the accessory renal artery was $38.4+/$ - 
10 and $36.6+/-11 \mathrm{~mm}$ on the right and the left side respectively in Indian origin. Single renal artery was found in all specimens except one in the present study.

The variations of renal arteries are studied by surgical and radiological anatomy and found bipolar supernumerary renal artery ${ }^{17}$. Pre caval right renal artery and its theory of development and its unusual vascular variations were also found ${ }^{18}$. Renal artery variations and their embryological basis and their surgical correlation were studied by Indian studies ${ }^{19}$. In their study bilateral perhilar multiple branching of the renal arteries in $11.66 \%$, duplication of renal arteries in $8.33 \%$ superior polar arteries in seven $6.66 \%$ were observed ${ }^{19}$. Shoja M.M et al $(2008)^{6}$ studied the prehilar branching pattern of renal artery. They observed fork pattern in 92.6\% kidneys, duplicate in $80.2 \%$, triplicate in $12.4 \%$ and ladder pattern in 7.4\% kidneys. Prehilar multiple branching of renal arteries were reported by Rao. M et al (2006) ${ }^{20}$. The embryological explanation of renal artery variations was presented by keibel. $\mathrm{F}$ and mall $\mathrm{F} \mathrm{P}^{7}$.

The variation of right and left kidneys and axis angle differences of accessory renal arteries in correlation with normal renal arterial axis were studied by radiological imaging methods by Joon Ho Choi M.D, Hyoung Jung Kim M.D ${ }^{21}$. Right renal artery arising ventrally from the abdominal aorta within $30^{\circ}$ from midline is considered to have an anterior origin while all other arteries are considered to have a lateral origin ${ }^{22}$. The renal artery with largest diameter supplying the kidney is considered as the main renal artery and all others were accessory renal arteries irrespective their positions ${ }^{22}$.

The accessory renal arteries were also described as supernumerary, multiple aberrant, additional etc ${ }^{3}$. Various comparative studies of abnormal renal arteries in human with other vertebrates to explain them on ontogenetic and phylogenetic basis were also studied ${ }^{23}$. Renal artery variations having great disparity from $11 \%$ to $61 \%$ were found in different social ethenic and racial differences were also observed. It is more common in Africans (37\%) and Caucasians (35\%) when compared with other populations and less common in Hindus $17 \%{ }^{23}$.

In our present study in one cadaver accessory renal arteries on both sides were found among cadavers.

CONCLUSION: Awareness of presence of precaval accessory right renal artery is important in pre surgical planning to avoid massive bleeding during laparoscopic surgeries, urological procedures, kidney transplants, vascular anomalies occurring in common surgical sites tends to increase the likelihood of damage during surgery. With unusual formations or the vascular anomalies the vulnerability in surgical procedures would be greater. Hence it is utmost important for surgeons to be aware of possible variations in order to prevent complications during surgery and diagnostic procedures. Knowledge of anomalous blood supply will reduce the risk during the surgical procedures. Abnormal position of blood vessels or variant positions of blood supply may be associated with clinical symptoms. It may affect hemodynamics. Hence knowledge of exact position of renal arteries and abnormal position of renal arteries is more important for surgical procedures.

\section{REFERENCES:}

1. Willam PL, Bannister LH, Berry MM, Collins P, Dyson M, Dussek JE et al. Cardiovascular System. In Grays Anatomy 38th Ed. Churchill Livingstone Edinburg 1995:1547. 
2. Willams PL, Warwick R. Dyson M. Bannister LH. Gray's Anatomy 37th edi. Churchill Livingstone. London 1989. PP: 218, 251.

3. Graves FT. The aberrant renal artery. J Anat 1956; 90: 553-58.

4. Petit P. Precaval right renal artery: have you seen this? AJR Am J Roentgenol.1997;169:317-31

5. Yeh BM, Coakley FV, Meng MV, Breiman RS, Stoller ML. Precaval right renal arteries: prevalence and morphological associations at spiral CT. Radiology. 2004:230:429-433.

6. Shoja MM, Tubbs RS, Shakeri A, Loukas M, Ardalan MR, Khosroshahi HT, Oakes WJ. Peri-hilar branching patterns and morphologies of the renal artery. a review and anatomical study, Surg Radiol Anat, 2008, 30(5): 375-382.

7. Keibel F, Mall FP (eds). Manual of human embryology, Vol.2, J.B. Lippincott, Philadelphia, 1912, 820-825.

8. Singh G, Ng YK, Bay BH. Bilateral accessory renal arteries associated with some anomalies of the ovarian arteries: a case study, Clin Anat, 1998, 11(6): 417-420.

9. Kadir S. Angiography of the kidneys. In: Kadir S. Diognostic angiography. Philadelphia, Pa: W.B. Saunders, 1986: 445-495.

10. Ozkan U, Oguzkurt L, Tercan F, Kizilkilic O, Koc Z, Koca N. Renal artery origins and variations: angiographic evaluation of 855 consecutive patients, Diagn interv Radiol, 2006, 12(4): 183-186

11. Netter FH. The Netter Collection of Medical Illustrations Volume 6, Kidneys, Ureters, and Urinary Bladder, Novartis. New Jersey 1997, p:17.

12. Saldarriage B, Perez AF, Ballesteros LE. A direct Anatomical study of additional renal arteries in a Colombian mestizo population. Folia Morphol 2008; 29: 41-76

13. Nayak S. Common celiaco-mesenterico-phrenic trunk and renal vascular variations, Saudi Med j, 2006, 27(12): 1894-1896.

14. Nayak S. Presence of accessory renal artery and kinking of aorta due to the abnormal origin of renal arteries. The internet Journal of Biological Anthropology. 2008; Volume 1 Number 2.

15. Anson BJ and Kurth LE. Common variations in the renal blood supply. Surg Gynae Obst 1955;100: 157-62.

16. Dhar P, Lal K. Main and accessory renal arteries - a morphological study. Department of anatomy, All India Institute of Medical Sciences, Delhi, 110029, India.

17. Shakeri Abolhassan, Shane Tubbs R., Shoja Mohammadali. Bipolar supernumerary renal artery. Surgical and Radiologic, Anatomy, Volume 29, Number 1, February 2007, pp. 89-92 (4).

18. Meng MV, Yeh BM, Breiman RS. Precaval right renal artery: description and embryologic origin. Department of Urology, University of California, San Francisco, School of Medicine, San Francisco, California 944143-0738, USA.

19. Virendra Budhiraja, Rakhi Rastogi, A.K.Asthana. Renal artery variations: embryological basis and surgical correlation, Department of Anatomy Subharti Medical College, Meerut, U.P., India.

20. Rao M, Bhat SM, Venkatramana V, Deepthinath R, Bolla SR. Bilateral Prehilar multiple branching of renal arteries: a case report and literature review, Kathmandu University Medical Journal (KUMJ), 2006, 4(3): 345-348.

21. Joon Ho Choi, Hyoung Jung Kim, Joo Won Lim. Radiologic Evaluation of the Renal Axis in Patients with an Accessory Renal Artery, Korean Soc Radiol 2010; 62: 263-269.

22. Anupma Gupta, Raman Gupta, Rikki Singhal. Precaval Right Renal Artery: A Cadaveric Study Incidence and Clinical Implications. Int BioL Med Res, 2011; 2(4): 1195-1197. 


\section{CASE REPORT}

23. Anupama Gupta, Reman Gupta, Rajan Kumar Singhla. The Accessory Renal Arteries: A comparative Study in Vertebrates with its Clinical Implications Journal of Clinical and Diagnostic Research. 2011 October, Vol-5(5): 970-973.

\section{AUTHORS:}

1. A. Vasanthi

2. K. P. S. Adinarayana

\section{PARTICULARS OF CONTRIBUTORS:}

1. Assistant Professor, Department of Anatomy, Andhra Medical College, Visakhapatnam.

2. Associate Professor, Department of Anatomy, Andhra Medical College, Visakhapatnam.

\section{NAME ADDRESS EMAIL ID OF THE} CORRESPONDING AUTHOR:

Dr. K.P.S. Adinarayana, 49-9-33, Lalithanagara, Visakhapatnam - 530016.

E-mail: kpsanarayana@rediffmail.com

Date of Submission: 21/12/2013.

Date of Peer Review: 02/01/2014.

Date of Acceptance: 25/01/2014.

Date of Publishing: 08/02/2014. 